Journal of Mechanical Engineering and Sciences (JMES)

ISSN (Print): 2289-4659; e-ISSN: 2231-8380; Volume 3, pp. 281-290, December 2012

(C) Universiti Malaysia Pahang, Pekan, Pahang, Malaysia

DOI: http://dx.doi.org/10.15282/jmes.3.2012.4.0026

\title{
EFFECT OF SOLUTIONIZING ON DRY SLIDING WEAR OF AL2024-BERYL METAL MATRIX COMPOSITE
}

\author{
Bhaskar H.B. ${ }^{1}$ and Abdul Sharief ${ }^{2}$ \\ ${ }^{1}$ Department of Mechanical Engineering, \\ Sri Siddhartha Institute of Technology, Maralur Post, Tumkur 572105, India \\ Tel: +91 948 1554400, Fax: +91 8162200270 \\ Email: bhaskarhbssit@gmail.com \\ ${ }^{2}$ Department of Mechanical Engineering, P.A. College of Engineering, \\ Mangalore 574153, India, Email: abdulsharief2010@gmail.com
}

\begin{abstract}
In the present investigation, A12024-Beryl particulate composites were fabricated by stir casting by varying the weight percentage of beryl particulates from $0 \mathrm{wt} \%$ to 10 $\mathrm{wt} \%$ in steps of $2 \mathrm{wt} \%$. The cast Al2024 alloy and its composites have been subjected to solutionizing treatment at a temperature of $495^{\circ} \mathrm{C}$ for $2 \mathrm{hrs}$, followed by ice quenching. Microstructural studies were carried out to determine the nature of the structure. The Brinell hardness test was conducted on both the Al2024 alloy and its composites before and after solutionizing. Pin-on disc wear tests were conducted to examine the wear behavior of the A12024 alloy and its composites. Sliding wear tests were conducted at various applied loads, sliding velocities and sliding distances. The results reveal that the wear rate of the composites is lower than that of the matrix alloy. The wear rate increased with an increasing applied load and sliding distance, and decreased with increasing sliding velocity.
\end{abstract}

Keywords: AMMC's; Beryl; solutionizing; sliding wear; BHN.

\section{INTRODUCTION}

Metal matrix composites (MMCs) are gaining widespread popularity in several technological fields owing to its improved mechanical properties when compared with conventional alloys (Surappa, 2003; Adebisi, Maleque, \& Rahman, 2011). Among the several categories of MMCs, aluminum-based composites are finding general acceptance, especially in applications where weight and strength are of prime concern. Presently, aluminum alloy-based MMCs are being used as candidate materials in several applications, such as pistons, pushrods, cylinder liners and brake discs, etc. (Hosking, Portillo, Wunderlin, \& Mehrabian, 1982; Pramila Bai, Ramasesh, \& Surappa, 1992). In recent years, aluminum alloys have gained popularity as a matrix material in the preparation of MMCs owing to their excellent mechanical properties and good corrosion resistance (Ramesh, Anwar Khan, Ravikumar, \& Savanprabhu, 2005; Ibrahim, Sapuan, \& Faieza, 2010; Bachtiar, Sapuan, \& Hamdan, 2010). The presence of hard reinforcement phases has endowed these composites with good tribological characteristics. These properties along with good specific strength and modulus make them a suitable alternative material for many engineering situations where sliding contact is expected. An extensive review on the dry sliding wear characteristics of aluminum alloy-based composites was undertaken by Sannino and Rack (1995). The aluminum-based composites exhibited excellent heat and wear resistance due to the 
superior hardness and heat resistance characteristics of the particles that are dispersed in the matrix alloy (Alpas \& Zhang, 1992). The heat-treated alloy and composite showed better strength and hardness, which results in fewer properties for crack nucleation and presented an enhancement in wear resistance (Sawla \& Das, 2004; Jeffrey, Tarlochan, \& Rahman, 2011). Al356 alloy-beryl composite was developed by both gravity die casting and squeeze casting techniques, followed by hot forging using closed die. Amongst these, hot forged composites showed improved hardness and tensile strength with decreasing wear rate (Suresh, Niranjan, Martin Jabraj, \& Chowdaiah, 2002). An improvement in both ultimate tensile strength and hardness were observed in hot forged composites. All these properties have been attributed to a refined microstructure due to the presence of beryl particulates, their uniform distribution, and the effects of pressure both during squeeze casting and after the forging of the composites (Suresh, Niranjan, Martin Jabraj, \& Chowdaiah, 2003). Venkataraman and Sundararajan (1996) studied sliding wear rate and friction as a function of reinforcement volume fraction. Al-SiCp composite pins were slid against a hardened steel disc, and concluded that wear rate decreases with increasing reinforcement content in the matrix material. Hoskings et al. (1982) reported a decrease in adhesive wear rate with increasing particle content, when Al2014 and Al2024 alloys were reinforced with $\mathrm{Al}_{2} \mathrm{O}_{3} \mathrm{p}$ and $\mathrm{SiCp}$ of various weight fractions. $\mathrm{SiC}$ was shown to be a more effective reinforcement than alumina in resisting wear. Narayan, Surappa, and Pramila Bai (1995) reported that seizure was associated with a rapid increase in wear rate, the transfer of MMC pin material to the counterface and increased noise and vibration. In the present work, Al2024 alloy and Al2024/Beryl MMCs were fabricated by a stir casting technique by varying the reinforcement from 0 wt. $\%$ to $10 \mathrm{wt} . \%$ in steps of 2 . The wear behavior of both the as-cast and solutionized A12024 alloy and its composites were characterized for various applied loads, sliding velocities and sliding distances.

\section{EXPERIMENTAL DETAILS}

\section{Selection of Material}

The matrix alloy selected for the development of composite material is $\mathrm{Al}-\mathrm{Cu}-\mathrm{Mg}$ alloy, designated by the aluminum association as A12024-T6. The chemical composition of the matrix material is given in Table 1. Beryl, which is naturally occurring, and is chemically beryllium-alumina-silicate $\left[\mathrm{Be}_{3} \mathrm{Al}_{2}\left(\mathrm{SiO}_{3}\right)_{6}\right]$, was used as the reinforcement material. The sizes of particles used were $45-65 \mu \mathrm{m}$ with a density of $2760 \mathrm{~kg} / \mathrm{m}^{3}$. The hardness of the reinforcement is 7.5 to 8.5 on the Mho's scale and has a hexagonal crystal structure. The chemical composition of the beryl particles used for the development of the composite are presented in Table 2.

Table 1. Composition of A12024 alloy (wt.\%)

\begin{tabular}{cccccccccccc}
\hline $\mathrm{Al}$ & $\mathrm{Cu}$ & $\mathrm{Fe}$ & $\mathrm{Mg}$ & $\mathrm{Mn}$ & $\mathrm{Si}$ & $\mathrm{Ti}$ & $\mathrm{Ni}$ & $\mathrm{Zn}$ & $\mathrm{Cr}$ & $\mathrm{Pb}$ & $\mathrm{Sn}$ \\
\hline 91.9 & 4.63 & 0.35 & 1.4 & 0.6 & 0.41 & 0.05 & 0.01 & 0.2 & 0.38 & 0.04 & 0.03 \\
\hline
\end{tabular}

Table 2. Composition of Reinforcement Material (wt.\%)

\begin{tabular}{cccccc}
\hline $\mathrm{SiO}_{2}$ & $\mathrm{Al}_{2} \mathrm{O}_{3}$ & $\mathrm{BeO}$ & $\mathrm{Fe}_{2} \mathrm{O}_{3}$ & $\mathrm{CaO}$ & $\mathrm{MgO}$ \\
\hline 68.01 & 16.74 & 12.01 & 1.91 & 0.86 & 0.08
\end{tabular}




\section{Development of Composites}

The Al2024 alloy and A12024-Beryl particulate reinforced composites were fabricated by liquid metallurgy. The matrix material was first superheated to above its melting temperature using a $5 \mathrm{KW}$ electrical resistance furnace, and preheated beryl particulates were added tothe molten metal. The molten metal was stirred for a duration of 8 minutes using a mechanical stirrer, and the speed of the stirrer was maintained at 300 to 350 rpm. The mixed molten metal at $710^{\circ} \mathrm{C}$ was poured into pre-heated cast iron molds. Al2024-Beryl composites were developed by adding a proportionate weight percentage of reinforcement from $0 \mathrm{wt} . \%$ to $10 \mathrm{wt} . \%$ in steps of $2 \mathrm{wt} . \%$. This liquid metallurgy route has been used for developing MMCs by many researchers (Basavarajappa \& Chandramohan, 2005; Krishnan, 1980; Ramesh, Swamy, \& Chandrashekar, 2011; Ramesh, Bharathesh, Verma, \& Keshavamurthy, 2012; Reddappa, Suresh, Niranjan, \& Satyanarayana, 2011; Skolianos \& Kattamis, 1993; Suresh et al., 2003; Xu \& Chung, 1988 ) because this method is the most economic for the fabrication of MMCs. The castings were tested to determine common casting defects using an ultrasonic flaw detector. The samples of Al2024 alloy and its composites were subjected to solutionizing treatment at a temperature of $495^{\circ} \mathrm{C}$ for a duration of $2 \mathrm{hrs}$ and then quenched in ice media.

\section{Testing of Composites}

Brinell hardness tests were carried out as per the ASTM-E10-93 standard. The hardness test was conducted as per HB 500 and the tester had a $10 \mathrm{~mm}$ diameter ball indenter. The tests were conducted at five locations on the sample to counter the possibility of the indenter resting on a hard particle, which may result in an anomalous value. A pin-ondisc test apparatus was used to investigate the dry sliding wear characteristics of the Al2024 alloy and its composites. The wear specimens were machined to a pin size of 8 $\mathrm{mm}$ diameter, $30 \mathrm{~mm}$ height and then polished. During the test the pin was pressed against the rotating counterpart EN32 steel disc of hardness 60HRC by applying a load. After running through a fixed sliding distance, the wear in $\mu \mathrm{m}$ and frictional force were tabulated. Each experiment was repeated three times, and the mean response values were considered. The wear test of both the as-cast and solutionized Al2024 alloy and its composites were characterized for various applied loads, sliding velocities and sliding distances. The same procedure was adapted by many other researchers when studying wear behavior (Howell and Ball, 1995; Park, 1992; Prasad \& Mecklenburg, 1993).

\section{RESULTS AND DISCUSSION}

\section{Microstructure Analysis}

Microstructural studies of the Al2024 alloy and its composites in the as-cast condition were conducted. The samples for microscopic examination were prepared by standard metallographic procedure, etched with killer's agent and examined under an optical microscope. Figure 1 shows the optical micrograph of the Al2024 alloy, Al2024/4wt.\% and A12024/6wt.\% beryl particulate composites. The micrographs clearly indicate the evidence of minimal porosity in both the Al2024 alloy and its Al2024/Beryl composites. The micrograph indicates the nearly uniform distribution of the reinforcement particles in the composite. 


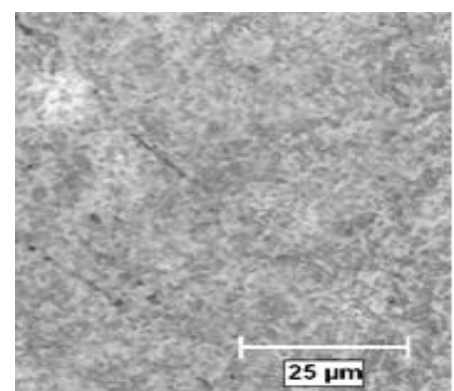

(a)

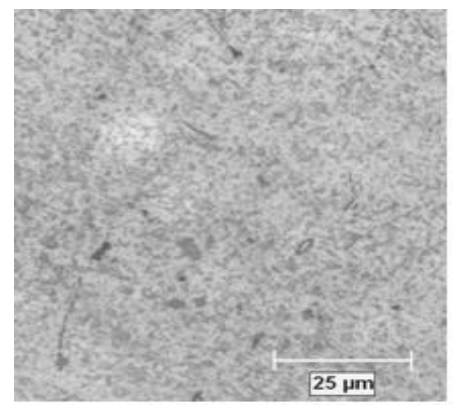

(b)

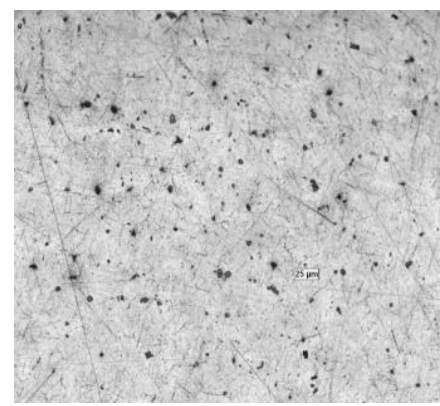

(c)

Figure 1. Micrograph of (a) Al2024 alloy, (b) Al2024/2 wt.\% and (c) Al2024/6 wt.\% beryl composites.

\section{Hardness}

The variation in Brinell hardness of the Al2024 alloy and its composites are shown in Figure 2. This indicates the effect of the reinforcement content in the matrix alloy on the Brinell hardness (HB 500). The hardness of the Al2024/10wt.\% beryl composite increased by around $37 \%$ compared to the Al2024 matrix alloy. It is also observed that with an increased content of beryl in the matrix alloy there was a significant improvement in the hardness of the composites. This trend is similar to the results of other researchers (Alpas \& Zhang, 1992; Das, Mondal, Sawla, \& Ramakrishnan, 2008; Kim \& Park, 1984; Kulkarni, Robi, Prasad, \& Ramakrishnan, 1996; Roy, Basu, \& Basu Mallick, 2005; Sawla \& Das, 2004; Song, Krauklis, Mouritz, \& Bandyopadhyay, 1995; Subramanian, 1992; Wahab, Daud, \& Ghazali, 2009; Wang \& Rack, 1991; Wu \& Li, 2000). This increase in hardness is expected since the beryl particulates, being a very hard ceramic material, contribute positively to the hardness of the composite. The hardness of the solutionized Al2024 alloy increases around by $29 \%$, while the solutionized Al2024-10 wt.\% of beryl composite shows an improvement in the hardness of around $47 \%$ compared to the as-cast matrix alloy.

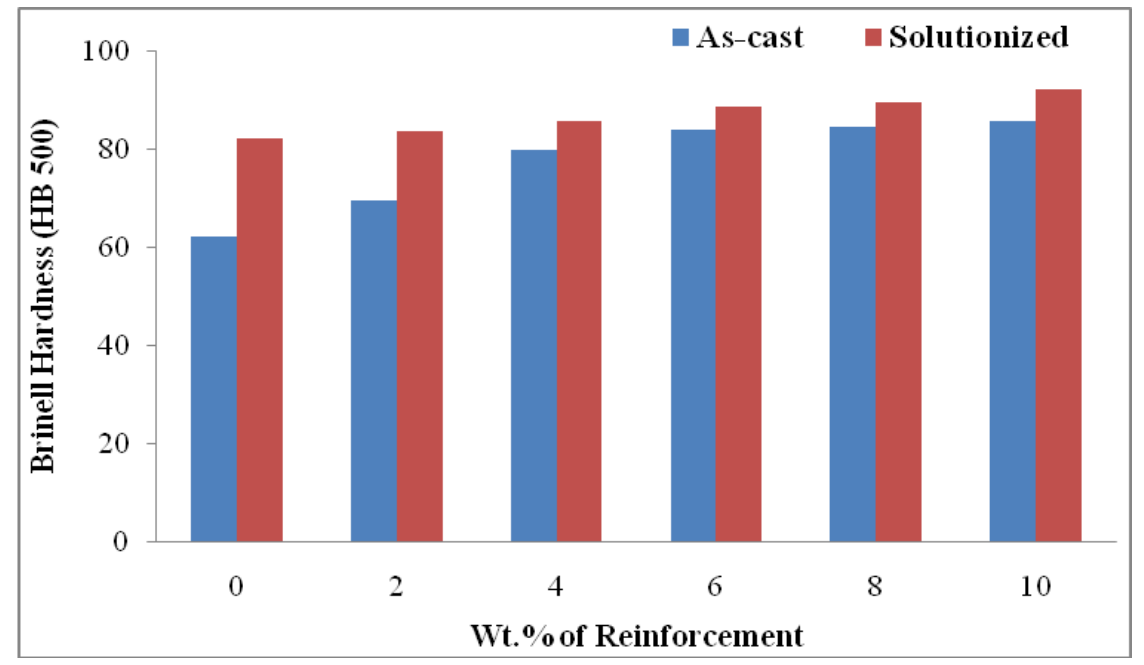

Figure 2. Effect of reinforcement on Brinell hardness of Al2024 alloy and its composites in as-cast and solutionized conditions. 


\section{Wear Characteristics}

\section{Effect of Reinforcement}

Figure 3 shows the effect of reinforcement on the wear rate of the as-cast, solutionized alloy and its composites for different wt.\% of reinforcement content at a constant load of $60 \mathrm{~N}$, sliding velocity of $3.456 \mathrm{~m} / \mathrm{s}$ and sliding distance of $4000 \mathrm{~m}$. It illustrates the influence of wt.\% of reinforcement on the wear rate of Al2024 alloy and composites against a EN8 steel counterface. It is observed that the wear rate of the composite decreases with an increased content of reinforcement in the matrix alloy, and also the wear rate decreases due to the solutionizing treatment. The decrease in wear rate is expected because of the greater hardness of the beryl particles. The solutionized alloy and its composites exhibit a minimum wear rate compared to the as-cast alloy and its composites.

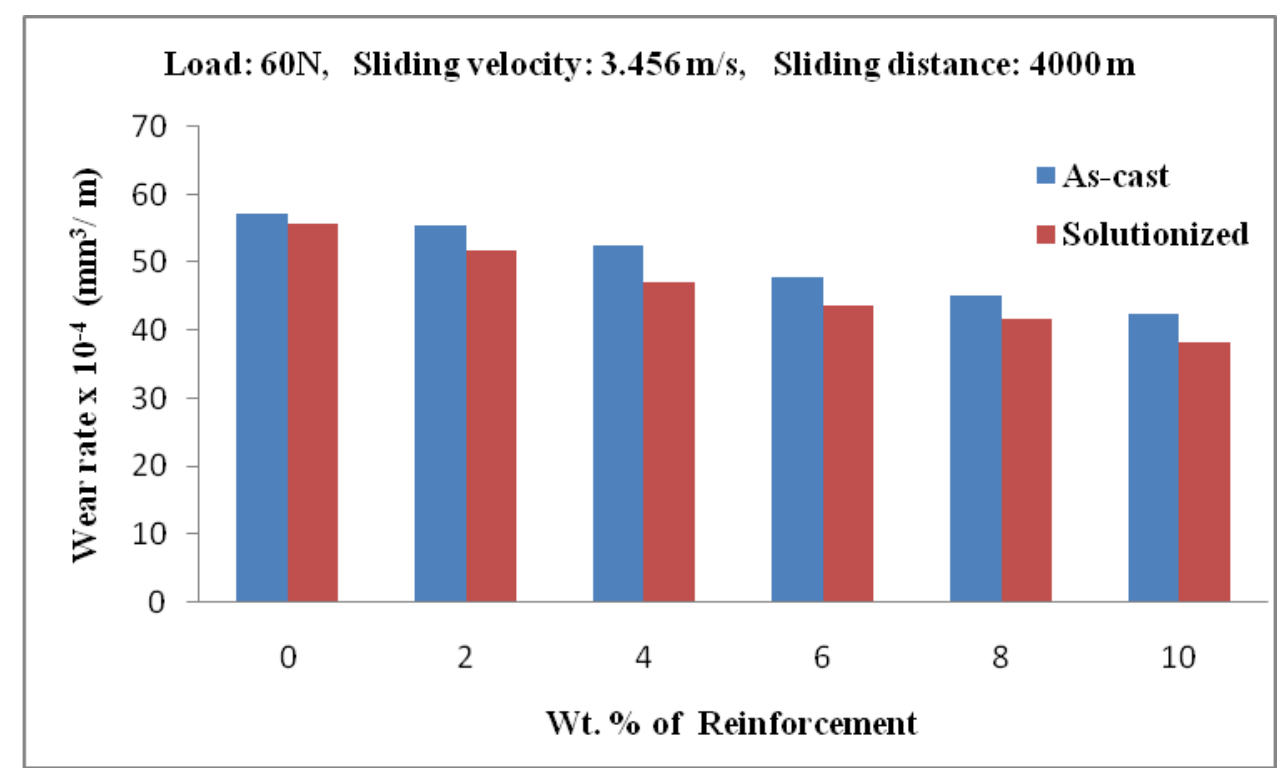

Figure 3. Effect of reinforcement on wear rate of Al2024 alloy and its composites.

\section{Effect of Applied load}

Figure 4 indicates the dependency of wear rate on the applied load for a constant sliding velocity of $3.456 \mathrm{~m} / \mathrm{s}$. The wear rate observed at a $20 \mathrm{~N}$ applied load is the minimum and as the load increases further the wear rate of the alloy and its composites increases for both the as-cast and solutionized conditions. The solutionizing treatment significantly minimizes the wear rate of the as-cast alloy and its composites. Due to the solutionizing treatment precipitation is formed in the alloy and its composites which in turn reduces the wear rate, and also the hard reinforcement particles protect the matrix alloy against wear, thus the wear resistance increases. 


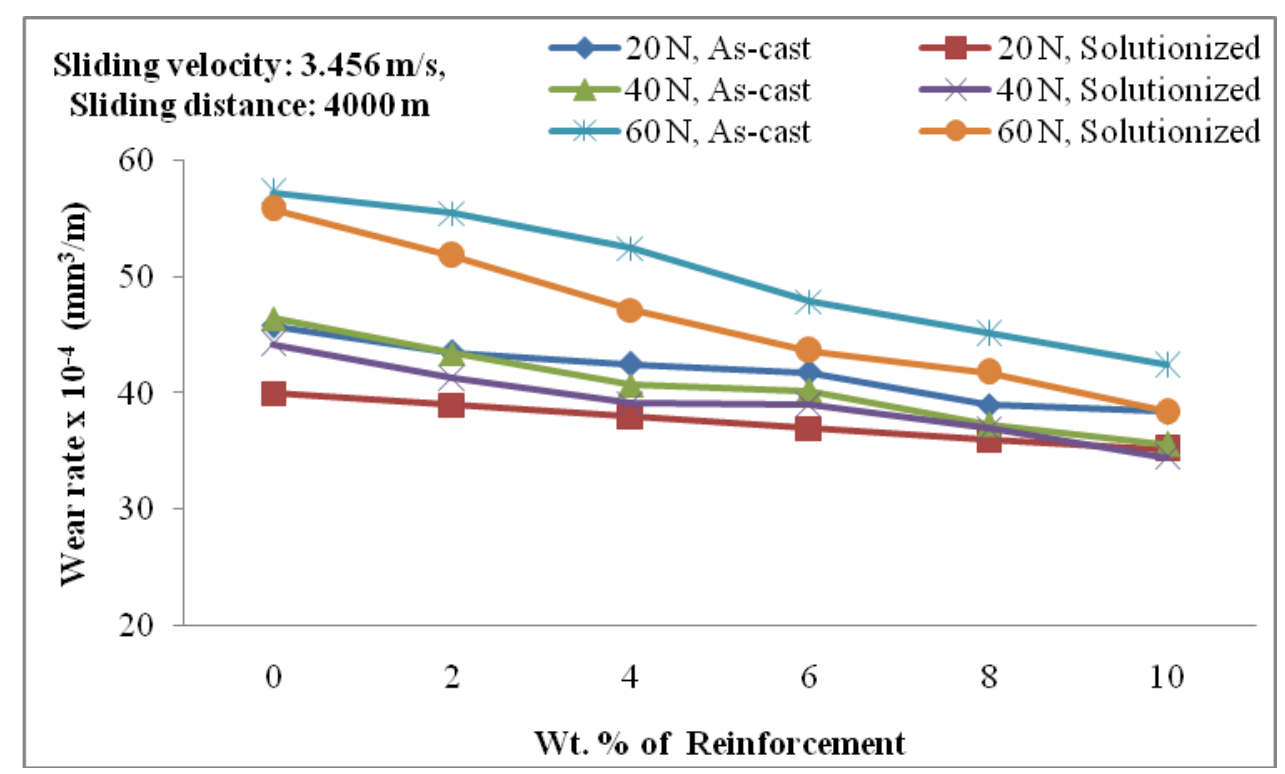

Figure 4. Variation in wear rate of Al2024 alloy and its composites for different loads in as-cast and solutionized conditions.

\section{Effect of Sliding Velocity}

Figure 5 shows the variation in wear rate of the A12024 alloy and its composites for different sliding velocities in the as-cast and solutionized conditions. The wear rate of the alloy and its composites in the as-cast and solutionized conditions decreases as the sliding velocity increases from $1.152 \mathrm{~m} / \mathrm{s}$ to $3.456 \mathrm{~m} / \mathrm{s}$ for a $60 \mathrm{~N}$ applied load and a sliding distance of $2000 \mathrm{~m}$, also the wear rate of the as-cast condition is higher than that of the solutionized alloy and its composites. During the experiment, heavy noise and vibration was observed which results in a minimum wear rate while increasing the sliding velocity.

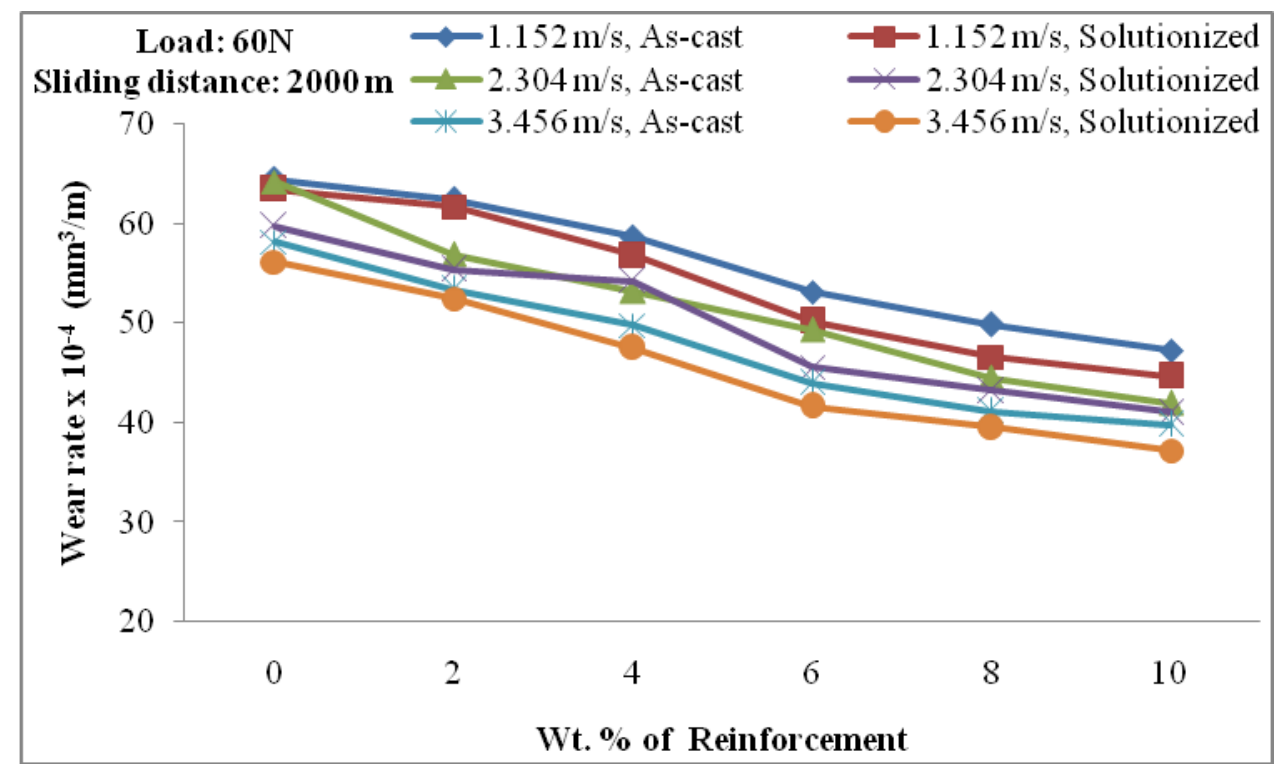

Figure 5. Variation in wear rate of A12024 alloy and its composites for different sliding velocities in as-cast and solutionized conditions. 


\section{Effect of Sliding Distance}

Figure 6 shows the variation in wear rate of the A12024 alloy and its composites for different sliding distances in the as-cast and solutionized conditions for different weight percentages of beryl particulate reinforcement, at a constant sliding velocity of 3.456 $\mathrm{m} / \mathrm{s}$ and for a $60 \mathrm{~N}$ applied load. As the reinforcement content increases, the wear resistance of the as-cast and solutionized composites increases, whereas the wear resistance of the solutionized composite is higher than that of the as-cast alloy and its composites. The wear resistance decreases as the sliding distance increases for the ascast and solutionized alloy and its composites. A similar trend was also observed independently for different sliding distances, applied loads and sliding velocities (Howell \& Ball, 1995; Reddappa et al., 2011; Skolianos \& Kattamis, 1993; Suresh et al., 2002; Venkataraman \& Sundararajan, 1996; Wu \& Li, 2000).

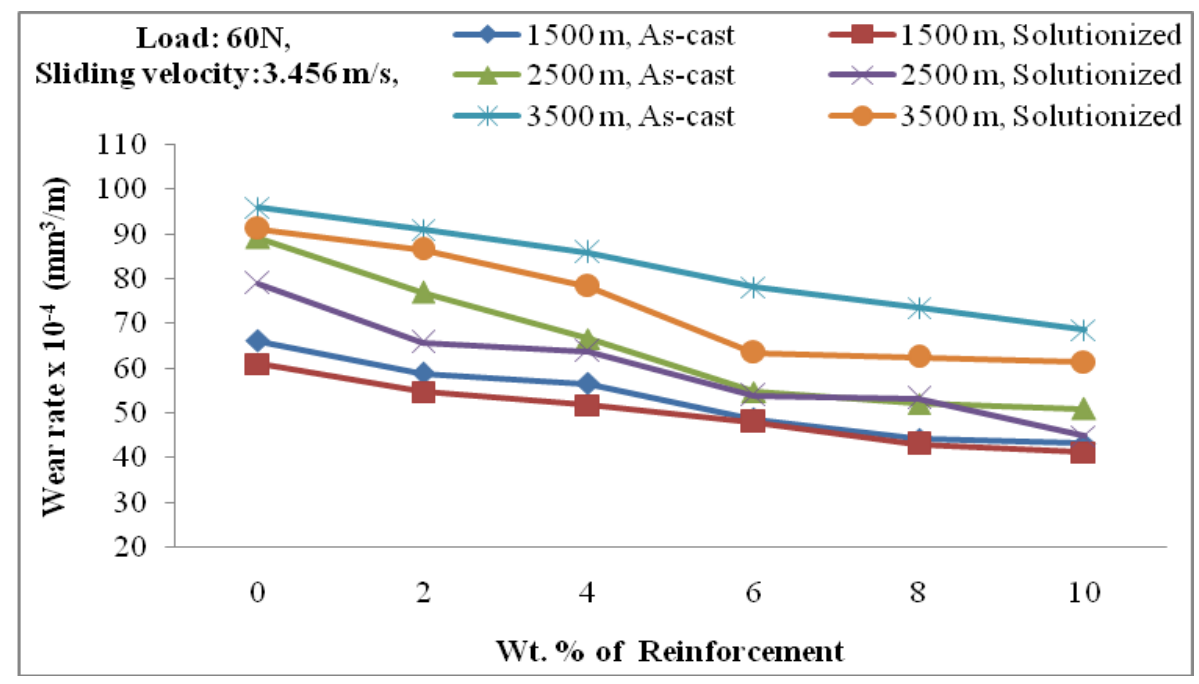

Figure 6. Variation in wear rate of Al2024 alloy and its composites for different sliding distances in as-cast and solutionized conditions.

\section{Worn Surface Analysis}

Figure 7 shows the worn surfaces of the as-cast and solutionized Al2024 alloy. The wear of the as-cast and solutionized Al2024 alloy was by plastic deformation and gouging. The wear in the solutionized alloy is minimal compared to the as-cast alloy, as can be observed from SEM which illustrates smaller groove formation during the wear test in the solutionized alloy. Figure 8 shows the SEM of the worn surfaces of the ascast and solutionized Al2024- 6 wt.\% beryl composites. The wear in the as-cast composite is slightly higher compared to the solutionized composite. The wear resistance of the composite material is improved due to the presence of hard reinforcement particles in the matrix material. The wear process in the composite material is by plastic deformation and gouging, and the reinforcement particles will crush to very minute particles and form a very thin sub surface layer, designated a mechanically-mixed layer (MML), which provides protection to the matrix material. The MML forms a layer between the work-hardened pin and the counterface that withstands high stresses and is very effective in reducing the sliding wear. It is evident that the solutionized composite material indicates superior wear resistance to that of the 
Al2024 alloy. This is because the improved hardness and strength of the composites results in the excellent wear resistance of the solutionized composite material.

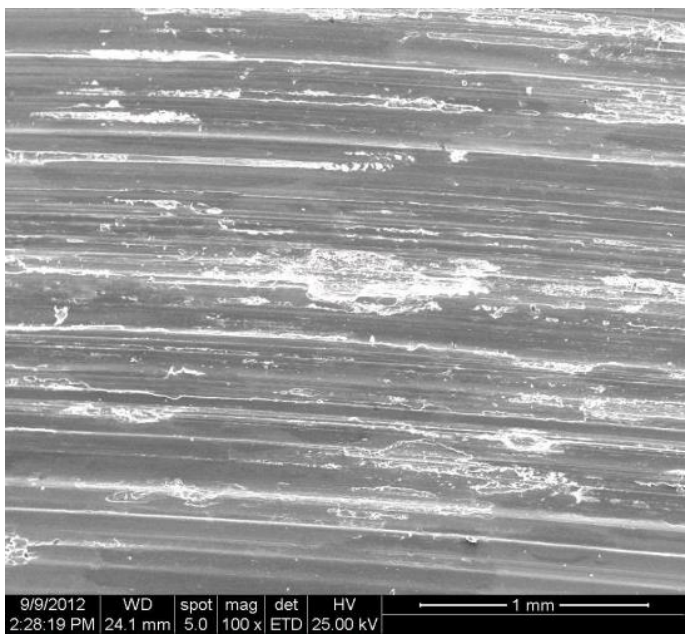

(a) As-cast Al2024 alloy

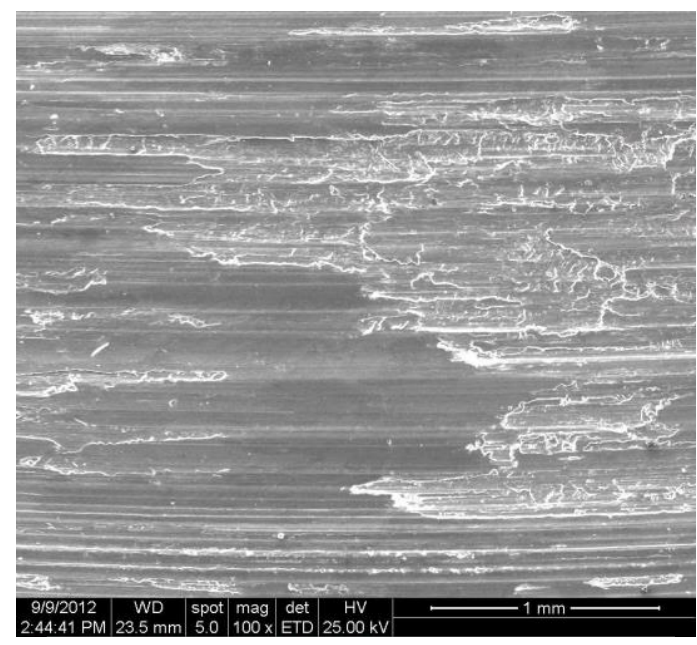

(b) Solutionized A12024 alloy

Figure 7. SEM of worn surfaces of as-cast and solutionized A12024 alloys.

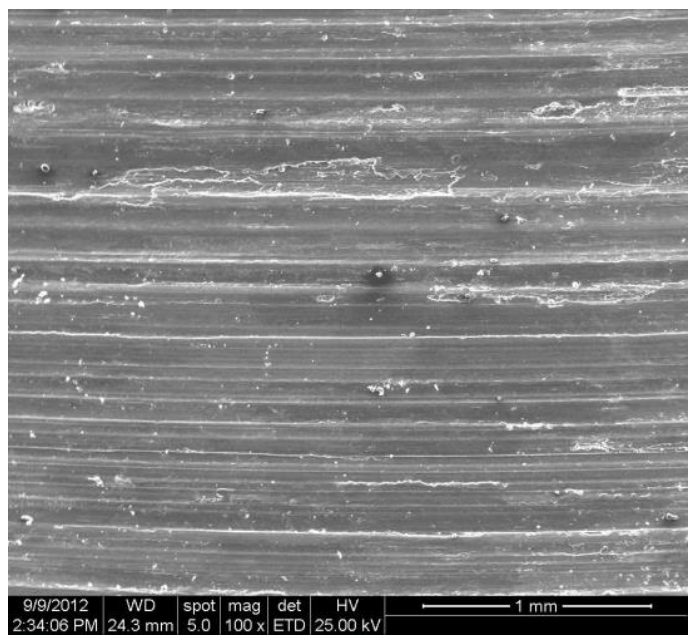

(a) As-cast Al2024-6 wt.\% Beryl Composite

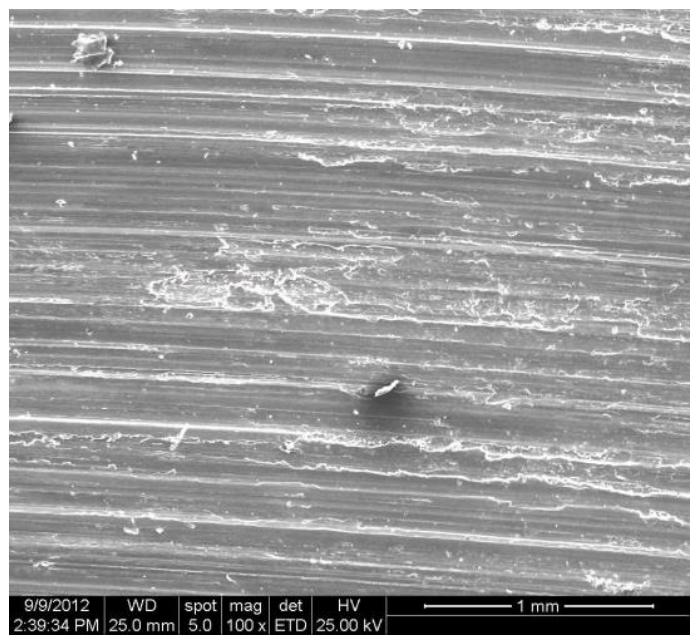

(b) Solutionized Al2024-6 wt.\% Beryl composite

Figure 8. SEM of worn surfaces of as-cast and solutionized Al2024-6 Wt.\% Beryl composites.

\section{CONCLUSIONS}

The Al2024-Beryl particulate reinforced composites were successfully developed using the liquid metallurgy method. The microstructural study clearly reveals a nearly uniform distribution of beryl particulates in the Al2024 matrix alloy. The hardness of the composites increases as the reinforcement content in the matrix alloy increases. The incorporation of beryl particles into the matrix alloy improves the sliding wear resistance of the composites compared to the matrix alloy. The wear rate of the composites as well as the matrix material increases as the sliding distance and applied load increases. Further, as the weight percentage of the reinforcement increases, the 
wear rate of the composite decreases. The wear rate of both the matrix alloy and the composites decreases as the sliding velocity increases. The solutionizing treatment has the greatest influence on increasing the wear resistance at varying applied loads and sliding distances.

\section{REFERENCES}

Adebisi, A. A., Maleque, M. A., \& Rahman, M. M. (2011). Metal matrix composite brake rotor: historical development and product life cycle analysis. International Journal of Automotive and Mechanical Engineering, 4, 471-480.

Alpas, A. T., \& Zhang, J. (1992). Effect of SiC particulate reinforcement on the dry sliding wear of aluminum-silicon alloys (A356). Wear, 155, 83-104.

Bachtiar, D., Sapuan, S. M., \& Hamdan, M. M. (2010). Flexural properties of alkaline treated sugar palm fibre reinforced epoxy composites. International Journal of Automotive and Mechanical Engineering, 1, 79-90.

Basavarajappa, S., \& Chandramohan, G. (2005). Dry sliding wear behaviour of hybrid metal matrix composites. Material Science, 11(3), 253-257.

Das, S., Mondal, D. P., Sawla, S., \& Ramakrishnan, N. (2008). Synergic effect of reinforcement and heat treatment on the two body abrasive wear of an $\mathrm{Al}-\mathrm{Si}$ alloy under varying loads and abrasive sizes. Wear, 264, 47-59.

Hosking, F. M., Portillo, F. F., Wunderlin, R., \& Mehrabian, R. (1982). Composites of aluminium alloys: fabrication and wear behaviour. Journal of Materials Science, 17(2), 477-498.

Howell, G. J., \& Ball, A. (1995). Dry sliding wear of particulate-reinforced aluminium alloys against automobile friction materials. Wear, 181-183, 379-390.

Ibrahim, M. S., Sapuan, S. M., \& Faieza, A. A. (2012). Mechanical and thermal properties of composites from unsaturated polyester filled with oil palm ash. Journal of Mechanical Engineering and Sciences, 2, 133-147.

Jeffrey, K. J. T., Tarlochan, F., \& Rahman, M. M. (2011). Residual strength of chop strand mats glass fiber/epoxy composite structures: effect of temperature and water absorption. International Journal of Automotive and Mechanical Engineering, 4, 504-519.

Kim, C. K., \& Park, S. Y. (1984). A study on the fabrication and mechanical properties of $\mathrm{SiC}$ fiber-aluminum alloy composites. Journal of Korean Institute of Metals and Materials, 22, 185-92.

Krishnan. B. P. (1980). Performance of an Al-Si-graphite particle composite piston in a diesel engine. Wear, 60, 205-215.

Kulkarni, M. D., Robi, P. S., Prasad, R. C., \& Ramakrishnan, P. (1996). Deformation and fracture behavior of cast and extruded 7075Al-SiCp composites at room and elevated temperatures. Materials Transactions JIM, 37(3), 223-229.

Narayan, M., Surappa, M. K., \& Pramila Bai, B. N. (1995). Dry sliding wear of Al alloy 2024- $\mathrm{Al}_{2} \mathrm{O}_{3}$, particle metal matrix composites. Wear, 181-183, 563-570.

Park, H. C. (1992). Wear behavior of hybrid metal matrix composite materials. Scripta Metallurgica, 27, 465-470.

Pramila Bai, B. N., Ramasesh, B. S., \& Surappa, M. K. (1992). Dry sliding wear of A356-Al-SiCp composites. Wear, 157(2), 295-304.

Prasad, S. V., \& Mecklenburg, K. R. (1993). Friction behavior of ceramic fiberreinforced aluminum metal-matrix composites against a 440C steel counterface. Wear, 162-164, 47-56. 
Ramesh, C. S., Anwar Khan, A. R., Ravikumar, N., \& Savanprabhu, P. (2005). Prediction of wear coefficient of $\mathrm{Al}_{6061-\mathrm{TiO}_{2}}$ composites. Wear, 259(1-6), 602608.

Ramesh, C. S., Bharathesh, T. P., Verma, S. M., \& Keshavamurthy, R. (2012). Sand abrasive wear behavior of hot forged Al6061- $\mathrm{TiO}_{2}$ composites. Journal of Materials Engineering and Performance, 21(1): 74-82.

Ramesh, D., Swamy, R. P., \& Chandrashekar, T. K. (2011). Abrasive wear behavior of Al6061-frit particulate composites. Journal of Mechanical Engineering and Technology, 3(2), 43-54.

Reddappa, H. N., Suresh, K. R., Niranjan, H. B., \& Satyanarayana, K. G. (2011). Effect of cold quenching on wear rate of al6061-beryl composites. International Journal of Engineering Science and Technology, 3(10), 7309-7315.

Roy, D., Basu, B., \& Basu Mallick, A. (2005). Tribological properties of Tialuminide reinforced Al-based in situ metal matrix composite. Journal of Intermetallics, $13,733-740$.

Sannino, A. P., \& Rack, H. J. (1995). Dry sliding wear of dis-continuously reinforced aluminium composites: review and discussion. Wear, 189(1-2), 1-19.

Sawla, S., \& Das, S. (2004). Combined effect of reinforcement and heat treatment on the two body abrasive wear of al-alloy and aluminum particle composites. Wear, $257,555-561$.

Skolianos, S., \& Kattamis, T. Z. (1993). Tribological properties of SiCp-reinforced $\mathrm{Al} 4.5 \% \mathrm{Cu}-1.5 \% \mathrm{Mg}$ alloy composites. Material Science Engineering A, 163: 107-113.

Song, W. Q., Krauklis, P., Mouritz, A. P., \& Bandyopadhyay, S. (1995). The effect of thermal ageing on the abrasive wear behavior of age-hardening $2014 \mathrm{Al} / \mathrm{SiC}$ and $6061 \mathrm{Al} / \mathrm{SiC}$ composites. Wear, 185, 125-130.

Subramanian, C. (1992). Some considerations towards the design of a wear resistant aluminium alloy. Wear, 155, 193-205.

Surappa, M. K. (2003). Metal matrix composites. In: Chidambaram, R. and Banerjee, S. (eds) Materials research: current scenario and future projections. New Delhi, Allied Publishers Pvt.

Suresh, K. R., Niranjan, H. B., Martin Jabraj, P., \& Chowdaiah, M. P. (2002). Dry sliding wear properties of Al356-beryl metal matrix composite. Proceedings of 3rd Asia-Australian Conference on Composite Materials (ACCM-3), Auckland, New Zealand, pp. 479-485.

Suresh, K. R., Niranjan, H. B., Martin Jabraj, P,. \& Chowdaiah, M. P. (2003). Tensile and wear properties of $\mathrm{Al}$ composites. Wear, 255, 638-642.

Venkataraman, B., \& Sundararajan, G. (1996). The sliding wear behaviour of Al-Sic particulate composites-I macro behaviour. Acta Metallurgica, 44, 451-460.

Wahab, M. N., Daud, A. R., \& Ghazali, M. J. (2009). Preparation and characterization of stir cast-aluminum nitride reinforced aluminum metal matrix composites. International Journal of Mechanical and Materials Engineering, 4(2), 115-117.

Wang, A., \& Rack, H. J. (1991) Abrasive wear of silicon carbide particulate and whisker reinforced 7091 aluminium matrix composites. Wear, 146, 337-348.

Wu, J. M., \& Li, Z. Z. (2000). Contributions of the particulate reinforcement to dry sliding wear resistance of rapidly solidified Al-Ti alloys. Wear, 244,147-153.

Xu, Y., \& Chung, D. D. L. (1988). Low volume fraction particulate performs for making metal matrix composites by liquid metal infiltration. Journal of Material Science, 33, 4707-4709. 